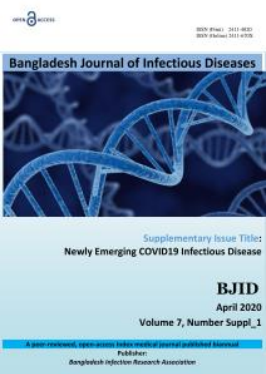

\title{
Covid19 Infection Caused by SARS CoV2: A Review
}

\author{
Zahid Dewan Shamim ${ }^{1}$, Md. Abdullah Yusuf ${ }^{2}$
}

${ }^{1}$ Senior Scientist, New York University, New York, USA; ${ }^{2}$ Assistant Professor, Department of Microbiology, National Institute of Neurosciences \& Hospital, Dhaka, Bangladesh

[Received: 20 March 2020; Accepted: 5 April 2020]

\begin{abstract}
SARS CoV2 infects the people worldwide and causes a disease named Covid19. It has been first discovered in Wuhan city of central China. Chinese people are presented with severe lung inflammatory pneumonia. No definite cause of their disease could be found, or they could not be cured by conventional anti-viral treatment. The market shoppers and buyers are infected at first through the evolution of any animal sold in the wholesale market of Huanan seafood in Wuhan city. Later, Chinese scientists are able to detect this new type of coronavirus through lab tests. SARS CoV2 has been first transmitted from animals to humans, it is currently able to transmit from human to human. So far, no specific medicine or vaccine has been developed for the disease; therefore, there is no way to cure the disease without intensive treatment at the hospital. This narrative review is written based on SARS CoV2 viral infection. [Bangladesh Journal of Infectious Diseases, April 2020; 7(Suppl_1):S32-S35]
\end{abstract}

Keywords: SARS CoV2; Covid19; Novel coronavirus

Correspondence: Dr. Zahid Dewan Shamim, Senior Scientist, New York University, New York, USA; Email: zndewan@hotmail.com

Conflict of interest: There is no conflict of interest to any of the authors of this article.

Contribution to authors: Shamim ZD involved in manuscript writing. Yusuf MA involved in revision of this manuscript

How to cite this article: Shamim ZD, Yusuf MA. Covid19 Infection Caused by SARS CoV2: A Review. Bangladesh J Infect Dis 2020;7(Suppl_1): S32-S35

Copyright: (2020. Shamim and Yusuf. Published by Bangladesh Journal of Infectious Diseases. This article is published under the Creative Commons CC BY-NC License (https://creativecommons.org/licenses/by-nc/4.0/). This license permits use, distribution and reproduction in any medium, provided the original work is properly cited, and is not used for commercial purposes.

\section{Introduction}

The number of people worldwide infected with the new dreaded coronavirus has exceeded 1.5 million $^{1}$. Therefore, far in the world more than 3,000 people have been infected with coronavirus and about 1 lakh have recovered from the disease. Authorities identified the new type of coronavirus in the city of Wuhan, the provincial capital of Hupei province in central China, in the middle of December 27th. At that time, about 3 Chinese people infected with the virus had severe lung inflammatory pneumonia, and at first, no clear cause of their disease could be found, or they could not be cured by conventional anti-viral treatment. The first virus is believed to have infected the market shoppers and buyers through the evolution of any animal sold in the wholesale market of Huanan seafood in Wuhan city $^{2}$. Later, Chinese scientists were able to detect this new type of coronavirus through lab tests. Although coronavirus was first transmitted from animals to humans, it is currently able to evolve 
from human to human. In addition to China, horrific coronavirus infections have spread and pandemics have spread to those countries, including South Korea, Iran, Japan, Singapore, Spain, Britain, Kuwait, Canada, Italy, Germany, Thailand, the United States, Australia, Bangladesh and France.

\section{Age Group}

According to the data so far, the transmission of Covid19 virus is higher in adults and older people and less in children ${ }^{3}$. Generally, the elderly are most at risk in the infected group, the harmful effects of the virus have been seen in the elderly and the mortality rate of the people in this group is highest.

\section{Bangladesh Situation}

Because there is no specific treatment for coronavirus patients, experts say urgent steps need to be taken to prevent the spread of coronavirus in Southeast Asia, as elsewhere in the world. According to the Imperial College of London model, a projection report says that in Bangladesh, the Corona pandemic can be infected with a total of eight million ${ }^{4}$. Hospital treatment may be required for many patient, ICU support of about seven lakh patients and five lakh patients may be required. There may be death. According to BRAC's research model, the Corona virus can kill 5 million people in Bangladesh $^{5}$. Needless to say, it is terrible and dangerous and dangerous for Bangladesh. Therefore, effective measures need to be taken immediately to prevent coronavirus in underdeveloped or poor countries like Bangladesh.

\section{Clinical Presentation}

There have been cases of transmission of the virus from person to person in different countries of the world. The virus can remain dormant for 2 to 7 days after being infected in the body and can be infected with another person's body during this time ${ }^{6}$. The World Health Organization has named the disease as a result of the virus infection - COVID-1 (coronavirus disease 2019- COVID-19). Symptoms of the disorder include fever, dry cough, shortness of breath, muscle aches and depression. The virus infection causes fever, fatigue, muscle pain, dry cough, respiratory and respiratory diseases bronchitis and pneumonia. Occasionally there may be cough with headache or cough. Symptoms generally do not appear to be as complex as a doctor's appearance until one week. But in the second week, the condition of the individual may deteriorate rapidly and severely. As the lungs increase, arterial blood shows a decrease in oxygen (hypoxemia) and the patient has to undergo oxygen treatment. Acute respiratory distress syndrome (ARDS or acute respiratory distress syndrome) is also observed ${ }^{7}$.

\section{Transmission}

There has also been evidence that the virus can be transmitted from person to person and has spread to those countries around the world. Touching hands with eyes, nose and mouth should be avoided, because the virus present in the environment can be touched by touch and can enter the body through the open space of the nose, mouth, eyes ${ }^{8}$. Spitting cannot be done on the streets and in places, because the virus can spread from the spit. Eating prepared foods in unhealthy environments on the road or elsewhere should be avoided, because of foods prepared in unhealthy environments.

\section{Complication}

If not treated properly, the disorder can be complicated, which can lead to lung inflammation, pneumonia, acute respiratory symptoms, acute immune response (sepsis) to blood, and bacterial infection (septic shock) and eventually death'. The hospital basically tries to relieve the symptoms of patients. This is a new virus. Research of cause of death is still going on. Cardiac involvement can cause sudden death.

\section{Laboratory Diagnosis}

Chinese scientists first confirmed the virus through the RT PCR test in the body of many people directly involved in the city of Wuhan and those who were not involved in the market ${ }^{10}$. However, there is still no clear idea of how deadly this new coronavirus is compared to the flu or other serous viruses. Blood tests of patients have shown that the virus reduces the number of white blood cells. In addition, liver and kidney damage occur among the Covid19 patients with high SGPT and serum creatinine.

\section{Immunity against SARS CoV2}

In coronavirus, 3 to 5 percent of the patients get better without treatment by the body's own immune system. Between 5 and 20 percent of infected patients require symptomatic treatment, and about 5 percent of patients need to be breathed mechanically in an intensive care unit or ICU, and sometimes oxygen is added to the blood by 
conducting blood inside the artificial lung ${ }^{11}$. In addition, there is a high likelihood of having a bacterial pneumonia due to extensive lung damage and occurs in $5.0 \%$ of intensive care patients ${ }^{12}$. People who already have low immunity are more likely to die of pneumonia.

\section{Mortality}

Coronary mortality was initially thought to be lower than the flu, according to current data, coronary mortality rate is 4 to 5 times higher than the $\mathrm{flu}^{12}$. The World Health Organization has commented that there is no alternative to test trials for patients suspected of having coronavirus disease. At the same time, they urged the concerned organizations to increase the production of medical equipment needed to overcome the crisis. Terrifying corona virus has infected worldwide and causes huge number of mortality and morbidity.

\section{Treatment}

Without symptomatic treatment, there is no specific treatment for a coronary infected patient. Thus, how can Corona virus infection be prevented and how to treat an infected patient? And who will serve as a fast-line defense in preventing and treating coronary virus infections? Everyone is worried about this. Needless to say, occupational health workers like doctors, nurses, assistants are working day and night with the risk of death as a fast-line defense in the prevention and treatment of this horrible coronary virus infection. Offices, courts, schools, colleges, shops, jute, restaurants, bars are shut down but hospitals open to treat the patient ${ }^{13}$. Hospitals will remain open and occupational health workers will have to provide treatment to patients. In this case, the American NIH has begun clinical trials of the drug "hydroxychloroquine" for the treatment of Covid19 patients. In fact, both chloroquine and hydroxychloroquine are used to treat malaria. In addition, these two drugs work to prevent the transmission of the virus.

\section{Prevention}

No new vaccine or antidote has been discovered since the virus is new, and there is no cure. Until March, 2021, no definitive anti-coronavirus vaccine or effective preventive vaccine has been discovered. The World Health Organization has already shown that people will be safe if the person regularly wash their hands thoroughly, cover their nose and mouth during coughing, stay away from cold and fluinfected people, do not travel without emergency, do not have any girdling, eat more water or juice. Immediately after attend in hospital, take the medication according to the symptoms, wear a mask if attacked, and trace the other contact persons including their spouse and children ${ }^{13}$. It is advisable not to hug or kiss the infected person. In addition, it is better not to intimate and terrified and follow the rules of prevention and stay healthy. People with fever, colds, coughs and sneezing should maintain a minimum distance of 3 to 6 feet, so that the virus particles floating in the air do not enter the body through breathing. Therefore, to prevent infection by coronavirus, it is mandatory to wash or clean the hands frequently with soap-water, alcohol or handsets, thus the virus in the hand is destroyed. During coughing or sneezing, the nose and mouth should be covered with temporary paper handkerchiefs or tissue paper, as well as the handkerchief dumped in the waste and hand washed with soap-water, so that the virus does not spread from person to person ${ }^{14}$.

\section{Conclusion}

The scientists and doctors from different countries, including the United States, Italy, China, are working day and night to discover new therapies for the prevention and treatment of this deadly virus. A clinical trial of the Corona vaccine phase-1 has begun in Washington state, USA. Corona Prevention Trust Force Committee Member. It may take one to one and a half year to discover the vaccine and bring it to market.

\section{References}

1. Lai CC, Shih TP, Ko WC, Tang HJ, Hsueh PR. Severe acute respiratory syndrome coronavirus 2 (SARS-CoV-2) and corona virus disease-2019 (COVID-19): the epidemic and the challenges. International journal of antimicrobial agents. 2020:105924

2. Rothan HA, Byrareddy SN. The epidemiology and pathogenesis of coronavirus disease (COVID-19) outbreak. Journal of autoimmunity. 2020:102433.

3. Shereen MA, Khan S, Kazmi A, Bashir N, Siddique R. COVID-19 infection: origin, transmission, and characteristics of human coronaviruses. Journal of Advanced Research. 2020 Mar 16.

4. Velavan TP, Meyer CG. The COVID-19 epidemic. Trop Med Int Health. 2020;25(3):278-80.

5. Ahmed SF, Quadeer AA, McKay MR. Preliminary identification of potential vaccine targets for the COVID-19 coronavirus (SARS-CoV-2) based on SARS-CoV immunological studies. Viruses. 2020;12(3):254.

6. Zu ZY, Jiang MD, Xu PP, Chen W, Ni QQ, Lu GM, Zhang LJ. Coronavirus disease 2019 (COVID-19): a perspective from China. Radiology. 2020:200490.

7. Zhang JJ, Dong X, Cao YY, Yuan YD, Yang YB, Yan YQ, Akdis CA, Gao YD. Clinical characteristics of 140 patients infected with SARS-CoV-2 in Wuhan, China. Allergy. 2020 Feb 19. 
8. Singhal T. A review of coronavirus disease-2019 (COVID19). The Indian Journal of Pediatrics. 2020:1-6.

9. Jiang F, Deng L, Zhang L, Cai Y, Cheung CW, Xia Z. Review of the clinical characteristics of coronavirus disease 2019 (COVID-19). Journal of General Internal Medicine. 2020:1-5.

10. Koh D. Occupational risks for COVID-19 infection. Occupational Medicine (Oxford, England). 2020;70(1):3.

11. Ruan Q, Yang K, Wang W, Jiang L, Song J. Clinical predictors of mortality due to COVID-19 based on an analysis of data of 150 patients from Wuhan, China. Intensive care medicine. 2020:1-3.
12. Wang LS, Wang YR, Ye DW, Liu QQ. A review of the 2019 Novel Coronavirus (COVID-19) based on current evidence. International Journal of Antimicrobial Agents. 2020:105948.

13. Devaux CA, Rolain JM, Colson P, Raoult D. New insights on the antiviral effects of chloroquine against coronavirus: what to expect for COVID-19? International journal of antimicrobial agents. 2020:105938.

14. Zhou D, Dai SM, Tong Q. COVID-19: a recommendation to examine the effect of hydroxychloroquine in preventing infection and progression. Journal of Antimicrobial Chemotherapy. 2020 Mar 20. 